\title{
Corrigendum: Periodontitis Is Associated With Risk of Conventional Stent Restenosis: Pilot Case-Control Study
}

OPEN ACCESS

Approved by:

Frontiers Editorial Office,

Frontiers Media SA, Switzerland

*Correspondence:

Mauro P. Santamaria

mauro.santamaria@unesp.br

Specialty section

This article was submitted to

Periodontics,

a section of the journal

Frontiers in Dental Medicine

Received: 04 May 2021

Accepted: 11 May 2021

Published: 26 May 2021

Citation:

Osugue R, Castro dos Santos NC,

Araujo CF, de Almeida FX, Feres M

and Santamaria MP (2021)

Corrigendum: Periodontitis is

Associated With Risk of Conventional

Stent Restenosis: Pilot Case-Control

Study. Front. Dent. Med. 2:705216.

doi: 10.3389/fdmed.2021.705216
Raphael Osugue ${ }^{1}$, Nidia C. Castro dos Santos ${ }^{1,2}$, Cassia F. Araujo ${ }^{1}$, Flavio X. de Almeida ${ }^{2}$, Magda Feres ${ }^{2}$ and Mauro P. Santamaria ${ }^{1 *}$

1 Division of Periodontics, Institute of Science and Technology, UNESP - São Paulo State University, São José dos Campos, Brazil, ${ }^{2}$ Dental Research Division, Guarulhos University, Guarulhos, Brazil

Keywords: atherosclerosis, cardiovascular disease, stent restenosis, periodontitis, inflammation

\section{A Corrigendum on}

Periodontitis Is Associated With Risk of Conventional Stent Restenosis: Pilot Case-Control Study

by Osugue, R., Castro dos Santos, N. C., Araujo, C. F., de Almeida, F. X., Feres, M., and Santamaria, M. P. (2021). Front. Dent. Med. 2:673626. doi: 10.3389/fdmed.2021.673626

In the original article, Magda Feres was incorrectly listed as the corresponding author. The correct corresponding author is Dr. Mauro Santamaria.

The authors apologize for this error and state that this does not change the scientific conclusions of the article in any way. The original article has been updated.

Copyright (@) 2021 Osugue, Castro dos Santos, Araujo, de Almeida, Feres and Santamaria. This is an open-access article distributed under the terms of the Creative Commons Attribution License (CC BY). The use, distribution or reproduction in other forums is permitted, provided the original author(s) and the copyright owner(s) are credited and that the original publication in this journal is cited, in accordance with accepted academic practice. No use, distribution or reproduction is permitted which does not comply with these terms. 